\title{
Volumetric Study of the Binary Mixtures Containing a Branched Hexane and an Isomeric Chlorobutane
}

\author{
Hernando Guerrero, Félix M. Royo and Carlos Lafuente*
}

Departamento de Química Física, Facultad de Ciencias, Universidad de Zaragoza, 50009 Zaragoza, Spain

\begin{abstract}
This paper reports densities at atmospheric pressure and at three temperatures $T=(283.15,298.15$, and 313.15) $\mathrm{K}$ of eight binary mixtures involving a branched hexane (3-methylpentane or 2,2-dimethylbutane) and each one of the isomeric chlorobutanes (1-chlorobutane, 2-chlorobutane, 1-chloro-2-methylpropane or 2-chloro-2-methylpropane). Excess volumes were calculated from experimental densities and correlated with the Redlich-Kister equation. Moreover, the excess volumes were analysed using the Prigogine-Flory-Patterson theory.
\end{abstract}

Keywords: Branched hexane, Isomeric chlorobutane, Prigogine-Flory-Patterson theory, Volumetric behaviour.

\section{INTRODUCTION}

In previous papers we have studied the volumetric behaviour of the systems formed by a linear alkane $(n-$ hexane or n-heptane) and a chloroalkane (1chloropropane or isomeric chlorobutanes) at several temperatures and at atmospheric pressure or at high pressures [1-3]. In order to study the influence of the ramification of the alkane on the excess volumes we present here the densities and the corresponding excess volumes at atmospheric pressure and at three temperatures $T=(283.15,298.15$, and 313.15$) \mathrm{K}$ of eight binary systems formed by a branched isomer of hexane (3-methylpentane or 2,2-dimethylbutane) and each one of the isomers of chlorobutane (1chlorobutane, 2-chlorobutane, 1-chloro-2methylpropane or 2-chloro-2-methylpropane).

Finally the Prigogine-Flory-Patterson theory $[4,5]$ was employed at $T=298.15 \mathrm{~K}$ to obtain the different contributions to excess volume.

A perusal of the literature shows that there are practically no studies on volumetric properties of these kinds of mixtures.

\section{EXPERIMENTAL}

The liquids used were: 3-methylpentane, 2,2dimethylbutane, 1-chlorobutane, 2-chlorobutane and 2chloro-2-methylpropane, ( $>99 \%)$ provided by Aldrich as well as 1-chloro-2-methylpropane (>99\%) obtained from Fluka. The purities of these compounds were checked by chromatographic methods and no further purification was needed.

*Address correspondence to this author at the Departamento de Química Física, Facultad de Ciencias, Universidad de Zaragoza, 50009 Zaragoza, Spain; Tel: +34976762295; Fax: +34976761202; E-mail: celadi@unizar.es
Densities, $\rho$, of both pure compounds and their mixtures, were determined using a vibrating tube densimeter Anton Paar DMA-5000, the temperature was controlled automatically within $\pm 0.001 \mathrm{~K}$. The uncertainty of the density measurements after proper calibration of the densimeter is $5 \times 10^{-6} \mathrm{~g}^{\circ} \mathrm{cm}^{-3}$. The mixtures were prepared by mass using a Sartorius CP225D balance, the estimated uncertainty in the mole fraction is $10^{-4}$.

The densities of the pure compounds at work temperatures properties together with density literature values at $T=298.15 \mathrm{~K}$ are collected in Table 1 [6-10].

\section{RESULTS AND DISCUSSION}

Excess volumes, $V^{E}$, were calculated from the density of the mixture, $\rho$, densities, $\rho_{\mathrm{i}}$, and molar masses, $M_{\mathrm{i}}$, of the pure compounds, and the corresponding molar fractions, $x_{i}$, by using the equation:

$V^{E}=x_{1}\left(\frac{M_{1}}{\rho}-\frac{M_{1}}{\rho_{1}}\right)+x_{2}\left(\frac{M_{2}}{\rho}-\frac{M_{2}}{\rho_{2}}\right)$

The experimental densities along with the calculated excess volumes can be found in the supplementary material. On the other hand, excess volumes are graphically represented in Figures 1-6.

The excess volumes, $V^{E}$, were correlated with a Redlich-Kister polynomial expansion [11]:

$Y^{E}=x_{1} x_{2} \sum_{i} A_{i}\left(x_{1}-x_{2}\right)^{i}$

being $A_{i}$ adjustable parameters and $x_{i}$ the mole fraction of component $i$; the number of parameters for each system has been chose in order to minimize the standard deviation. The values of these parameters

(C) 2015 Lifescience Global 
Table 1: Densities of the Pure Compounds at Work Temperatures and Comparison with Literature Data at $T=298.15 \mathrm{~K}$

\begin{tabular}{|c|c|c|c|c|}
\hline \multirow{2}{*}{ Compound } & \multirow{2}{*}{$\begin{array}{l}T=283.15 \mathrm{~K} \\
\rho^{\exp } / \mathrm{g} \cdot \mathrm{cm}^{-3}\end{array}$} & \multicolumn{2}{|c|}{$T=298.15 \mathrm{~K}$} & \multirow{2}{*}{$\begin{array}{l}T=313.15 \mathrm{~K} \\
\rho^{\exp } / \mathrm{g} \cdot \mathrm{cm}^{-3}\end{array}$} \\
\hline & & $\rho^{\exp } / \mathbf{g} \cdot \mathbf{c m}^{-3}$ & $\rho^{\text {lit }} / \mathbf{g} \cdot \mathbf{c m}^{-3}$ & \\
\hline 3-Methylpentane & 0.673277 & 0.659654 & $0.65967[6]$ & 0.645693 \\
\hline 2,2-Dimethylbutane & 0.658465 & 0.644407 & $0.64450[7]$ & 0.629991 \\
\hline 1-Chlorobutane & 0.897339 & 0.880785 & $0.88075[8]$ & 0.863882 \\
\hline 1-Chloro-2-methylpropane & 0.888845 & 0.871533 & $0.8719[10]$ & 0.853902 \\
\hline 2-Chloro-2-methylpropane & 0.855249 & 0.837096 & $0.83711[9]$ & 0.818536 \\
\hline
\end{tabular}

together with the standard deviations $\sigma\left(V^{E}\right)$ are given in Table 2.

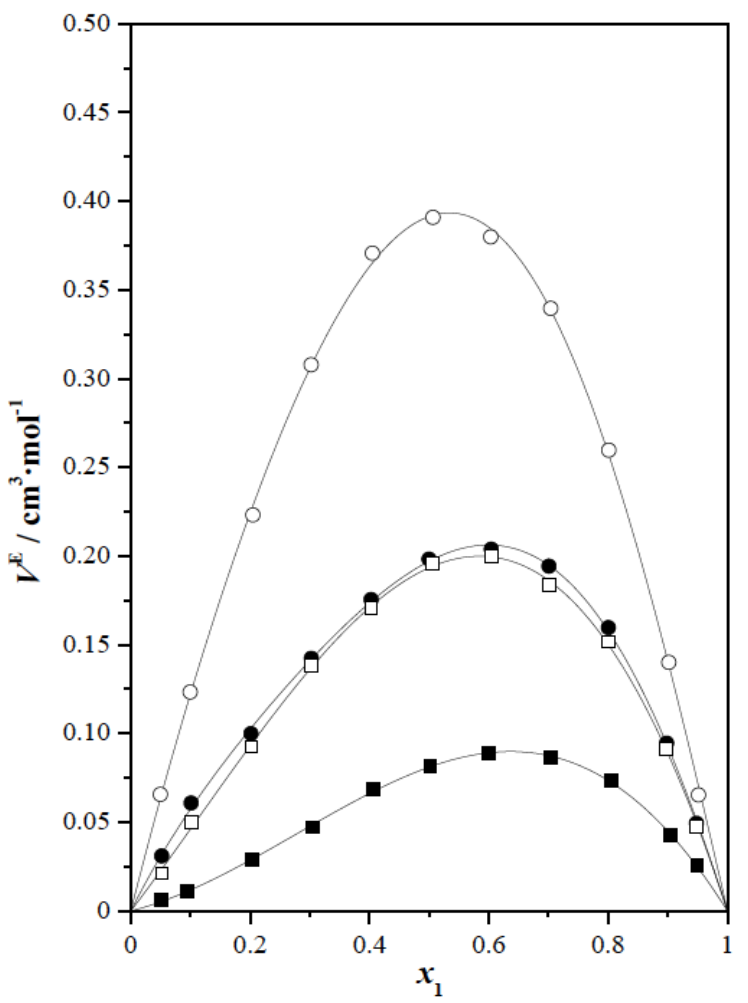

Figure 1: Excess volume, $V^{E}$, for 3-methylpentane (1) + isomeric chlorobutane (2) at $T=283.15 \mathrm{~K}$ as a function of mole fraction, $x_{1}$ : 1-chlorobutane $(\square)$, 2-chlorobutane $(\bullet), 1$ chloro-2-methylpropane $(\square)$, 2-chloro-2-methylpropane $(\bigcirc)$.

The mixtures containing 3-methylpentane show positive excess volumes through the complete range of compositions at the three temperatures. For a given temperature the excess volumes increase following the sequence: 1-chlorobutane < 1-chloro-2-methylpropane $<2$-chlorobutane $<2$-chloro-2-methylpropane, although the $V^{E}$ values for 1-methyl-2-chloropropane and 2chlorobutane are quite similar specially at $T=283.15$ K. For the system 3-methylpentane + 2-chloro-2- methylpropane the maximum $V^{E}$ values are centered while for the rest of the isomeric chlorobutanes the maximum is shifted to the zone rich in alkane. With respect to the temperature behaviour, the excess volumes increase for the four binary mixtures in a similar way. It can be outlined that the excess volumes of the mixtures 3-methylpentane + isomeric chlorobutane and $n$-hexane + isomeric chlorobutane is very similar, altough the $V^{E}$ values for these last mixtures are higher.

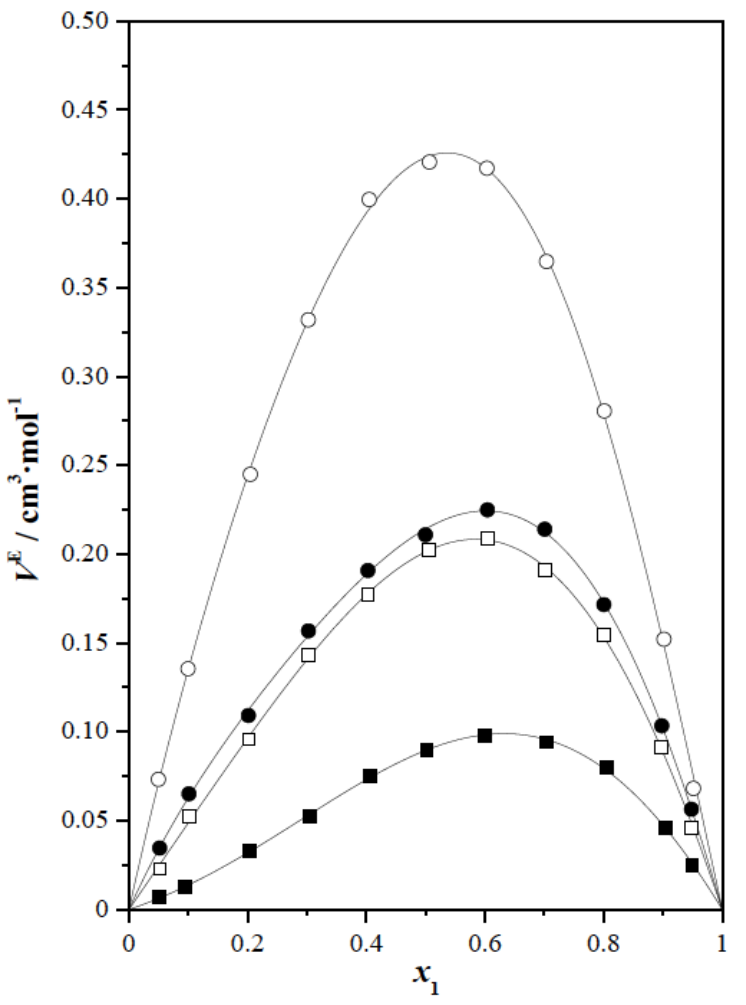

Figure 2: Excess volume, $V^{E}$, for 3-methylpentane (1) + isomeric chlorobutane (2) at $T=298.15 \mathrm{~K}$ as a function of mole fraction, $x_{1}$ : 1-chlorobutane $(\boldsymbol{\square}), 2$-chlorobutane $(\mathbf{O}), 1$ chloro-2-methylpropane ( $\square$ ), 2-chloro-2-methylpropane (○). 


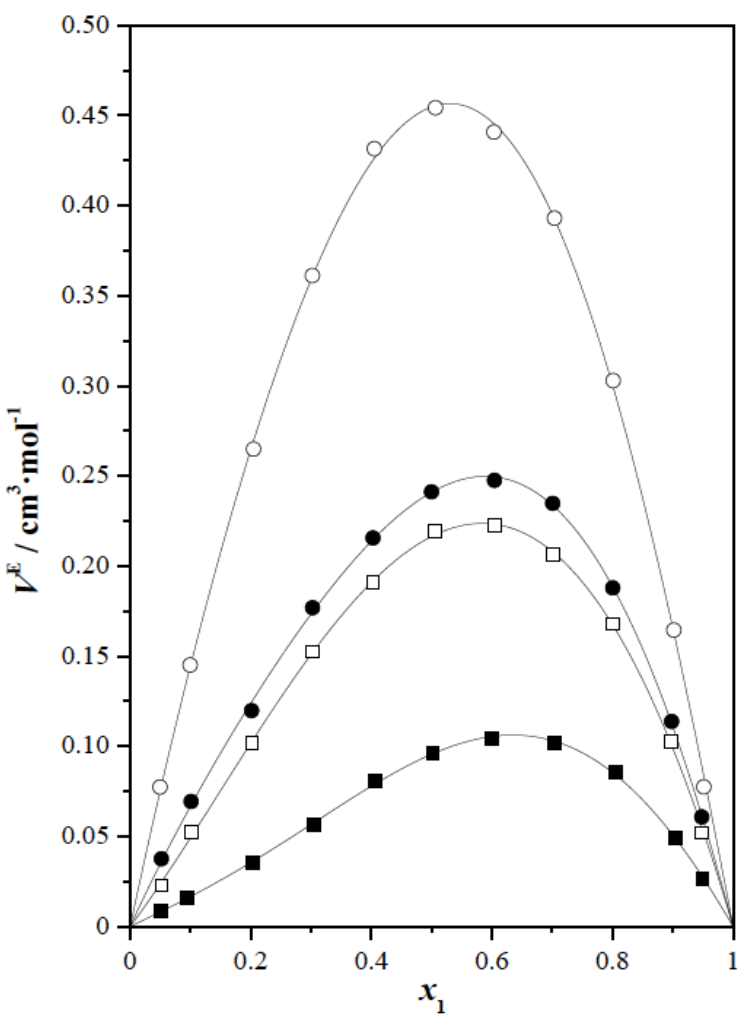

Figure 3: Excess volume, $V^{E}$, for 3-methylpentane (1) + isomeric chlorobutane (2) at $T=313.15 \mathrm{~K}$ as a function of mole fraction, $x_{1}$ : 1-chlorobutane $(\boldsymbol{\square}), 2$-chlorobutane $(\mathbf{O}), 1$ chloro-2-methylpropane ( $\square$ ), 2-chloro-2-methylpropane (○).

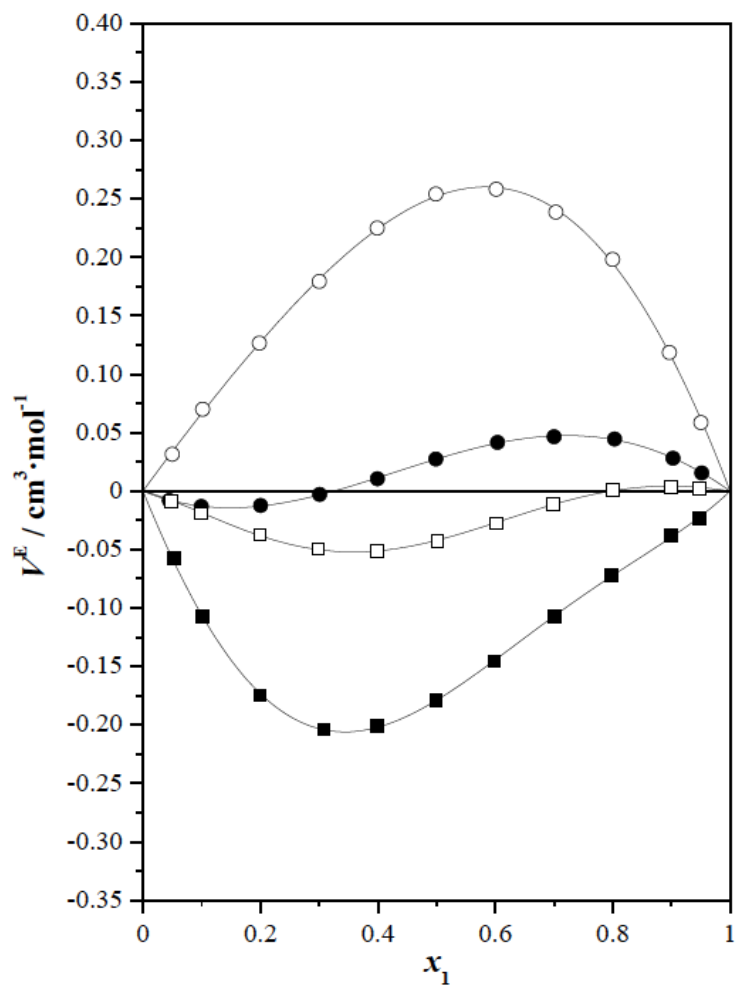

Figure 4: Excess volume, $V^{E}$, for 2,2-dimethylbutane (1) + isomeric chlorobutane (2) at $T=283.15 \mathrm{~K}$ as a function of mole fraction, $x_{1}$ : 1-chlorobutane $(\boldsymbol{\square})$, 2-chlorobutane $(\mathbf{O})$, 1chloro-2-methylpropane ( $\square$ ), 2-chloro-2-methylpropane (○).

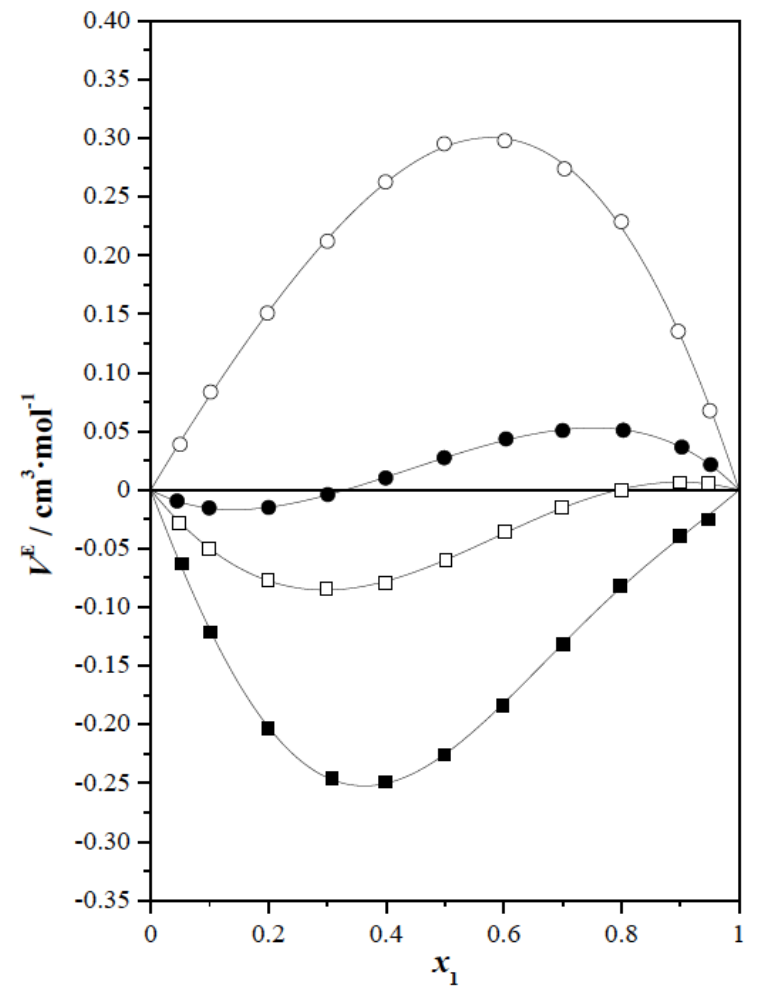

Figure 5: Excess volume, $V^{E}$, for 2,2-dimethylbutane (1) + isomeric chlorobutane (2) at $T=298.15 \mathrm{~K}$ as a function of mole fraction, $x_{1}$ : 1-chlorobutane $(\boldsymbol{\square}), 2$-chlorobutane $(\mathbf{0})$, 1chloro-2-methylpropane $(\square)$, 2-chloro-2-methylpropane $(\bigcirc)$.

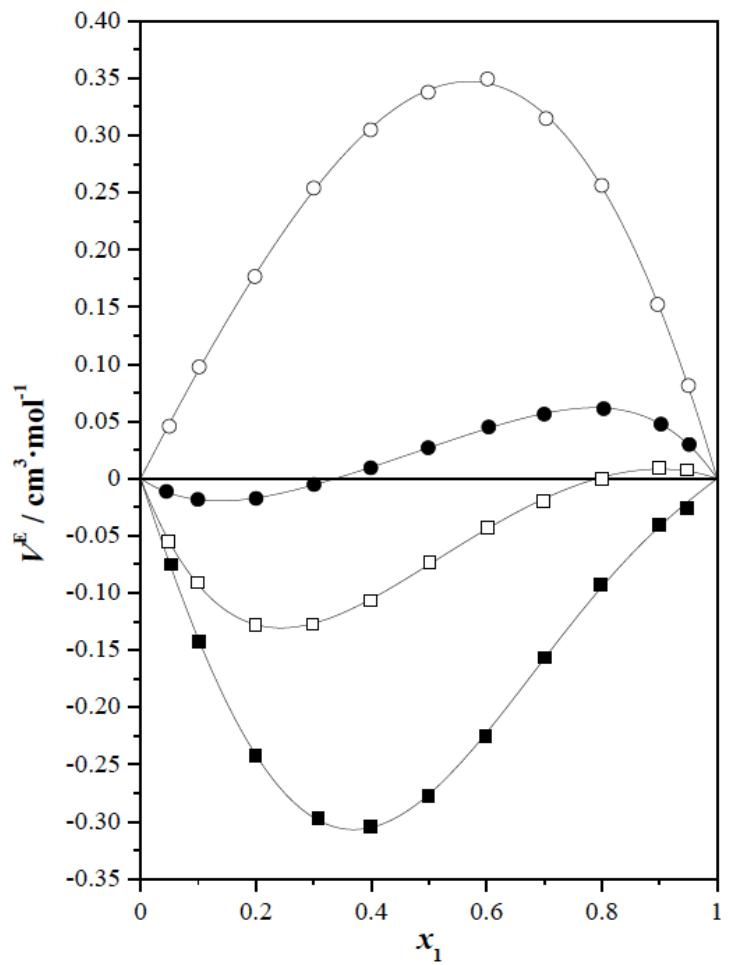

Figure 6: Excess volume, $V^{E}$, for 2,2-dimethylbutane (1) + isomeric chlorobutane (2) at $T=313.15 \mathrm{~K}$ as a function of mole fraction, $x_{1}$ : 1-chlorobutane $(\square)$, 2-chlorobutane $(\mathbf{0})$, 1 chloro-2-methylpropane $(\square)$, 2-chloro-2-methylpropane $(\bigcirc)$. 
Table 2: Parameters and Standard Deviations of the Redlich Kister Equation

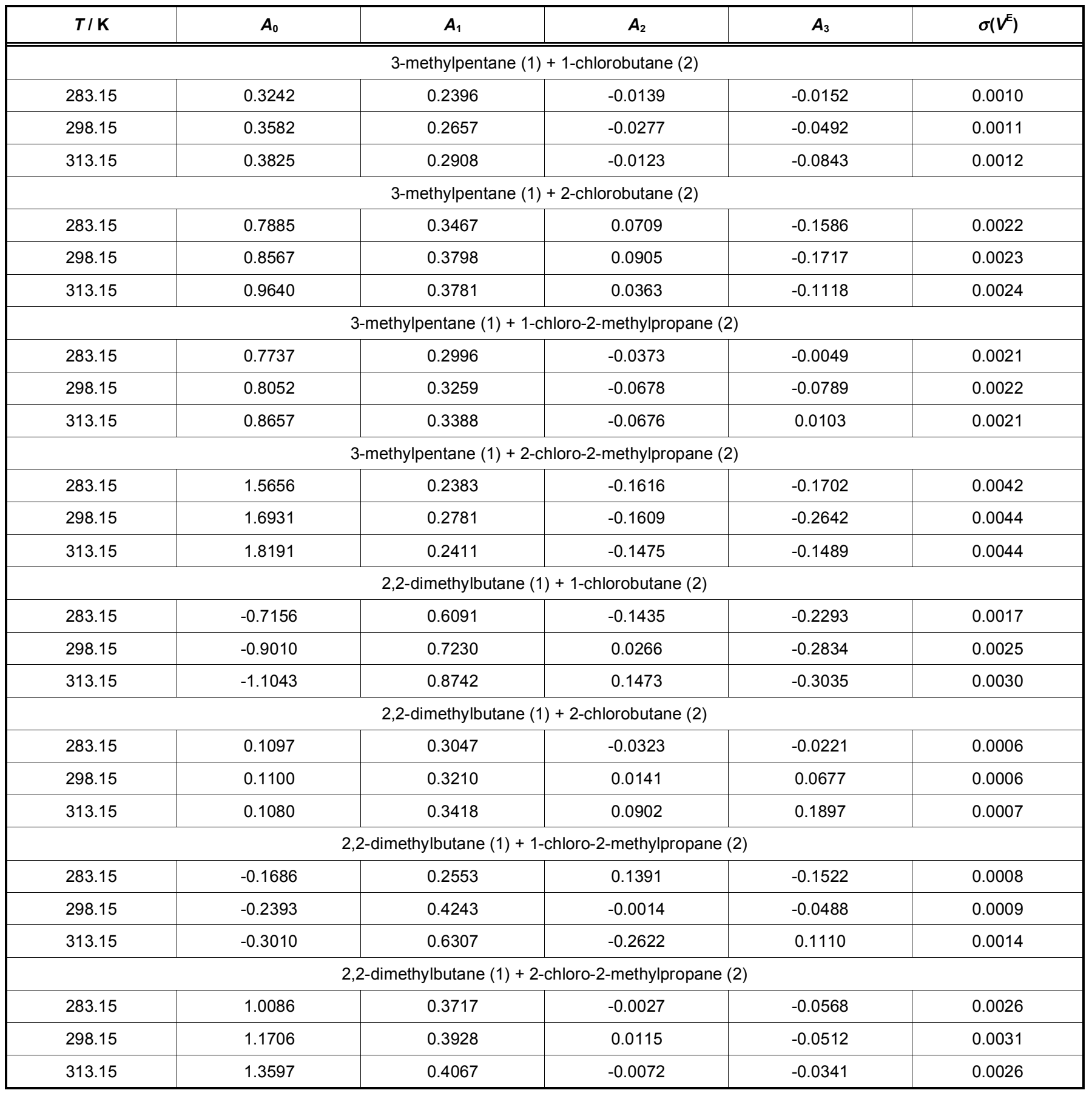

The behaviour of excess volumes for the mixtures containing 2,2-dimethylbutane is a bit more complex. The system 2,2-dimethylbutane + 1-chlorobutane show negative $V^{E}$ values at all temperatures studied while the mixture of 2,2-dimethylbutane with 2-methyl-2chloropropane present positive $V^{E}$ values at the three temperatures. Finally, the remaining systems show an intermediate behaviour, presenting the $V^{E}$ plots a sigmoidal shape with slightly negative values a low mole fractions of 2,2-dimethylbutane and positive values in the richer alkane region. Considering a given temperature the excess volumes increase following the same sequence as in the mixtures with 3methylpentane, that is: 1-chlorobutane < 1-chloro-2methylpropane $<2$-chlorobutane $<2$-chloro-2methylpropane, but the values are lower. On the other hand, when temperature increases the $V^{E}$ values increase in absolute value, that is the positive excess volume become more positive and the negative ones become more negative. 
In a general way the excess volumes are the result of different energetic and structural effects. The weakness of the dipole-dipole interactions between chloroalkane molecules when the alkane molecules are added leads to positive $V^{E}$ values. On the other hand, the changes in the free volume in the mixing process and the interstitial acommodation of the components have a negative effect on excess volumes. This contribution is more notable in the case of mixtures involving 1-chlorobutane, its flexibility allows a better accommodation among the alkane molecules, while for 2-chloro-2-methylpropane the interstitial acommodation is worse and consequently the excess volumes are positive and moderately high.

\section{PRIGOGINE-FLORY-PATTERSON THEORY}

The Prigogine-Flory-Patterson theory considers the excess volume of a mixture as the sum of three contributions $[5,6]$ : the interactional contribution that is proportional to the Flory or interaction parameter, $\chi_{12}$, the free volume contribution and the internal pressure contribution. The final expression for $V^{E}$ is:

$$
\begin{aligned}
& \frac{V^{E}}{x_{1} V_{1}^{*}+x_{2} V_{2}^{*}}=\frac{\left(\tilde{V}^{1 / 3}-1\right) \tilde{V}^{2 / 3}}{(4 / 3) \tilde{V}^{-1 / 3}-1} \psi_{1} \theta_{2} \frac{\chi_{12}}{P_{1}^{*}} \\
& -\frac{\left(\tilde{V}_{1}-\tilde{V}_{2}\right)\left[(14 / 9) \tilde{V}^{-1 / 3}-1\right]}{\left[(4 / 3) \tilde{V}^{-1 / 3}-1\right] \tilde{V}} \psi_{1} \psi_{2} \\
& +\frac{\left(\tilde{V}_{1}-\tilde{V}_{2}\right)\left[(14 / 9) \tilde{V}^{-1 / 3}-1\right]}{P_{1}^{*} \psi_{2}+P_{2}^{*} \psi_{1}}\left(P_{1}^{*}-P_{2}^{*}\right) \psi_{1} \psi_{2}
\end{aligned}
$$

In this equation the reduced volume for the mixture, $\tilde{V}$, has been obtained from the reduced volumes of the pure compounds by using:

$\tilde{V}=\psi_{1} \tilde{V}_{1}+\psi_{2} \tilde{V}_{2}$

where the contact energy fraction, $\psi_{i}$, is defined as: $\psi_{1}=1-\psi_{2}=\frac{x_{1} P_{1}^{*} V_{1}^{*}}{x_{1} P_{1}^{*} V_{1}^{*}+x_{2} P_{2}^{*} V_{2}^{*}}$

The rest of the parameters can be obtained using Flory's theory $[12,13]$. Physical properties of the pure compounds [14, 15] together with calculated Flory's parameters are given in Table $\mathbf{3}$, the number of contact sites per segment of a molecule, $s$, has been calculated using the method proposed by Bondi [16].

The interaction parameter $\chi_{12}$, for each mixture has been estimated from experimental equimolar $V^{E}$ values by fitting the Prigogine-Flory-Patterson theory. The $\chi_{12}$ values are reported in Table 4 along with the calculated contributions to excess volume.

The interactional contribution to $V^{E}$ is positive for all the mixtures except for the system 2,2-dimethylbutane +1 -chlorobutane, showing the existence of specific interactions between the mixed compounds. This contribution is greater when the alkane is 3methylpentane although for the system 2,2dimethylbutane + 2-chloro-2-methylpropane this contribution is also significative. The free volume contribution that depends mainly on the differences between the reduced volumes of the components is negative for all the mixtures although for the systems containing 2-chloro-2-methylpropane this contribution is very small due to this compound present a reduced volume very similar to the reduced volume of the alkanes. The internal pressure contribution that depends on both the differences between the reduced volumes and the internal pressures of the components is negative for the mixtures studied here except for the system 2,2-dimethylbutane + 2-chloro-2-methylpropane that present slightly positive values because the reduced volume and internal pressure of 2-chloro-2methylpropane are closer to the values for the alkanes, specially in the case of 2,2-dimethylbutane.

Table 3: Physical Properties and Calculated Flory Parameters of the Pure Compounds at $T=298.15 \mathrm{~K}$

\begin{tabular}{|c|c|c|c|c|c|}
\hline Compound & $\alpha_{\mathrm{p}} / \mathbf{k K}^{-1}$ & $\boldsymbol{\kappa}_{\mathrm{T}} / \mathbf{T P a}{ }^{-1}$ & $P^{*} / \mathbf{J} \cdot \mathbf{c m}^{-3}$ & $\tilde{\boldsymbol{s}} / \AA^{-1}$ \\
\hline \hline 3-Methylpentane & 1.3972 & 1725.72 & 391.43 & 1.3381 & 1.411 \\
\hline 2,2-Dimethylbutane & 1.4781 & 2015.85 & 423.03 & 1.3238 & 1.441 \\
\hline 1-Chlorobutane & 1.2640 & 1232.68 & 516.20 & 1.2994 & 1.424 \\
\hline 2-Chlorobutane & 1.3087 & 1366.07 & 488.52 & 1.3078 & 1.410 \\
\hline 1-Chloro-2-methylpropane & 1.3123 & 1341.73 & 499.21 & 1.3084 & 1.422 \\
\hline 2-Chloro-2-methylpropane & 1.4614 & 1675.35 & 463.65 & 1.3352 & 1.446 \\
\hline
\end{tabular}


Table 4: Interaction Parameter, $\chi_{12}$, and PFP Excess Volume Contributions at Equimolar Composition and at $T=$ 298.15 K

\begin{tabular}{|c|c|c|c|c|c|}
\hline System & $V_{P F P}^{E} / \mathrm{cm}^{3} \cdot \mathrm{mol}^{-1}$ & $\chi_{12} / \mathrm{J} \cdot \mathrm{cm}^{-3}$ & $\begin{array}{c}\Delta V_{\text {int }} I \\
\mathbf{c m}^{3} \cdot \mathbf{m o l}^{-1}\end{array}$ & $\begin{array}{c}\Delta V_{f v} l \\
\mathbf{c m}^{3} \cdot \mathbf{m o l}^{-1}\end{array}$ & $\begin{array}{c}\Delta V_{P^{*}} l \\
\mathrm{~cm}^{3} \cdot \mathrm{mol}^{-1}\end{array}$ \\
\hline \multicolumn{6}{|c|}{ 3-Methylpentane + } \\
\hline 1-chlorobutane & 0.0894 & 14.17 & 0.3768 & -0.0490 & -0.2384 \\
\hline 2-chlorobutane & 0.2140 & 14.10 & 0.3942 & -0.0302 & -0.1501 \\
\hline 1-chloro-2-methylpropane & 0.2011 & 14.10 & 0.3911 & -0.0289 & -0.1611 \\
\hline 2-chloro-2-methylpropane & 0.4231 & 13.87 & 0.4344 & -0.0003 & -0.0111 \\
\hline \multicolumn{6}{|c|}{ 2,2-Dimethylbutane + } \\
\hline 1-chlorobutane & -0.2255 & -3.83 & -0.0957 & -0.0199 & -0.1099 \\
\hline 2-chlorobutane & 0.0273 & 3.36 & 0.0881 & -0.0086 & -0.0523 \\
\hline 1-chloro-2-methylpropane & -0.0600 & 0.22 & 0.0057 & -0.0079 & -0.0578 \\
\hline 2-chloro-2-methylpropane & 0.2925 & 9.34 & 0.2729 & -0.0044 & 0.0239 \\
\hline
\end{tabular}

\section{CONCLUSIONS}

This work presents the experimental densities of the binary mixtures containing a branched alkane (3methylpentane or 2,2-dimethylbutane) and an isomeric chlorobutane (1-chlorobutane, 2-chlorobutane, 1chloro-2-methylpropane or 2-chloro-2-methylpropane) over the whole composition range at three temperatures $(283.15,298.15$ and $313.15 \mathrm{~K})$. From these experimental data excess volumes of the mixtures were calculated and correlated using a Redlich-Kister polynomial expansion.

The mixtures containing 3-methylpentane show positive excess volumes while the excess volumes of the mixtures formed by 2,2-dimethylbutane show more complexity. Presenting positive $V^{E}$ values for 1chlorobutane and negative $V^{E}$ values for 2-methyl-2chloropropane being the excess volume behavior of the rest of the mixtures containing 2,2-dimethylbutane intermediate between these two extremes.

Finally we have used the Prigogine-Flory-Patterson theory to analyze the results. The interactional and the internal pressure are the main contributions to $V^{E}$.

\section{ACKNOWLEDGEMENTS}

The authors are indebted for financial assistance from Diputación General de Aragón (D.G.A.) and Fondo Social Europeo "Construyendo Europa desde Aragón".

\section{SUPPLEMENTAL MATERIALS}

The supplemental materials can be downloaded from the journal website along with the article.

\section{REFERENCES}

[1] Alonso E, Guerrero $H$, Montaño D, Lafuente C, Artigas, $H$. Thermophysical study of the $n$-hexane or $n$-heptane with 1chloropropane systems. Thermochim Acta 2011; 525: 71-7. http://dx.doi.org/10.1016/j.tca.2011.07.023

[2] Guerrero H, Pera G, Giner I, Bandrés I, Lafuente C. Volumetric and acoustic behaviour of systems containing nhexane, or n-heptane and isomeric chlorobutanes Algebraic representation of thermodynamic properties and the classification of solutions. J Chem Thermodyn 2010; 42: 1406-12.

http://dx.doi.org/10.1016/j.jct.2010.06.008

[3] Guerrero H, Cea P, Gascón I, Royo FM, Lafuente C. Volumetric study of the mixtures n-hexane plus isomeric chlorobutane: experimental characterization and volume translated Peng-Robinson predictions. J Phys Chem B 2013; 117: 10284-92.

http://dx.doi.org/10.1021/jp407380a

[4] Van HT, Patterson D. Volumes of mixing and the $\mathrm{P}^{*}$ effect. 1 Hexane isomers with normal and branched hexadecane. $J$ Solution Chem 1982; 11: 793-805. http://dx.doi.org/10.1007/BF00650519

[5] Costas M, Patterson D. Volumes of mixing and the $P^{*}$ effect 2. Mixtures of alkanes with liquids of different internal pressures. J Solution Chem 1982; 11: 807-21. http://dx.doi.org/10.1007/BF00650520

[6] Aucejo A, Cruz Burguet M, Munoz R, Marques JL. Densities, viscosities, and refractive indices of the binary liquid systems n-alkanes + isomers of hexane at $298.15 \mathrm{~K}$. J Chem Eng Data 1995; 40: 871-4. http://dx.doi.org/10.1021/je00020a029

[7] Ohnishi K, Fujihara I, Murakami S. Thermodynamic properties of decalins mixed with hexane isomers at 298.15 K. I. Excess enthalpies and excess isobaric heat capacitie. Fluid Phase Equilib 1989; 46: 59-72. http://dx.doi.org/10.1016/0378-3812(89)80275-4

[8] Kovacs E, Aim A, Linek J. Excess molar volumes of (an alkane+1-chloroalkane) at $\mathrm{T}=298.15 \mathrm{~K}$. J Chem Thermodyn 2001; 33: 33-45.

\section{http://dx.doi.org/10.1006/jcht.2000.0714}

[9] Dahmani O, Wichterle I, Ait-Kaci A, Isothermal vapour-liquid equilibria for binary systems of chloroalkanes with heptane, toluene and methylcyclohexane at 323.15 and $333.15 \mathrm{~K}$. Fluid Phase Equilib 1996; 124: 135-46. http://dx.doi.org/10.1016/S0378-3812(96)03106-8 
[10] TRC Thermodynamics Table Hydrocarbons and NonHydrocarbons, Selected values of Properties of Chemical Compounds, Thermodynamic Research Center, Texas A\&M University College Station, TX.

[11] Redlich O, Kister AT. Algebraic representation of thermodynamic properties and the classification of solutions. Ind Eng Chem 1948; 40: 345-8.

http://dx.doi.org/10.1021/ie50458a036

[12] Flory PJ, Orwoll RA, Vrij A. Statistical thermodynamics of chain molecule liquids. I. Equation of state for normal paraffin hydrocarbons. J Am Chem Soc 1964; 86: 3507-14. http://dx.doi.org/10.1021/ja01071a023

[13] Abe A, Flory PJ. Thermodynamics properties of mixtures of small non-polar molecules. J Am Chem Soc 1965; 87: 1838-46. http://dx.doi.org/10.1021/ja01087a003
[14] Guerrero H, García-Mardones M, Pérez-Gregorio V, Gascón I, Lafuente C. Experimental and VTPR-predicted volumetric properties of branched hexanes. Fluid Phase Equilib 2013; 338: 141-7.

http://dx.doi.org/10.1016/j.fluid.2012.11.013

[15] Guerrero H, Ballesteros LM, García-Mardones M, Lafuente C, Gascón I. Volumetric properties of short-chain chloroalkanes. J Chem Eng Data 2012; 57: 2076-83. http://dx.doi.org/10.1021/je3003805

[16] Bondi A. Van der Waals volumes + radii. J Phys Chem 1964; 68: 441-51. http://dx.doi.org/10.1021/j100785a001 